\title{
Operating Room
}

National Cancer Institute

\section{Source}

National Cancer Institute. Operating Room. NCI Thesaurus. Code C53516.

A room in a health care facility equipped for the performance of surgical operations and procedures. 